\title{
GARAGE LOCATION SELECTION FOR RESIDENTIAL HOUSE BY WASPAS-SVNS METHOD
}

\author{
Romualdas BAUŠYS, Birute JUODAGALVIENE் \\ Department of Graphical Systems, Faculty of Fundamental Sciences, Vilnius Gediminas Technical University, \\ Sauletekio al. 11, Vilnius LT-10223, Lithuania
}

Received 09 Mar 2016; accepted 30 Nov 2016

\begin{abstract}
The paper deals with the location selection problem of the garage at the parcel of a single-family residential house. The mathematical model for this real life problem is constructed within MCDM framework. The significance of the chosen criteria was evaluated by AHP approach. The formulated MCDM problem is solved applying WASPAS extension, namely WASPAS-SVNS. The applied single-valued neutrosophic set allows to modeling uncertainty of the initial information explicitly. A numerical example is considered in order to verify the proposed approach.
\end{abstract}

Keywords: garage location, residential house, MCDM, WASPAS, neutrosophic set.

\section{Introduction}

Human comfort (well-being, physical and mental condition, security) is closely related to the development of functional architectural space in residential house design process. The quality of the architectural, functional space design is investigated in the context of a residential house and a garage. The position of these residential house spaces provides physical and psychological comfort, which results in the achievement of the main design goal. The Committees of the Regions Housing and Regional Policy have formed an opinion already some time ago on the quality of the residential housing (EUR-Lex 2007a).

After the restoration of Lithuania's independence, the situation with parcel ownership has changed (now they are inherited, bought, sold, etc.), so in the cities and suburbs constructions of single-family residential houses have increased. In 2007, the Ministry of the Environment carried out the survey (about 413,000 villages, towns, district centers and urban residents were interviewed) which results showed that most people would choose his own residential house (82.6 percent) (AM 2007). Therefore, the selection of the garage a place is important problem. According to European statistical data (Eurostat 2014), 33.7 percent of the population lived in single-family dwellings in 28 countries in the territory of Europe in 2014. The percentage is the highest in Croatia, Slovenia or Hungary, and although Lithuania is lagging behind the above-mentioned countries it still exceeds the average of mentioned statistics.
The United Nations Economic Commission for Europe (UNECE) already in 2006 stressed that the quality of housing plays a crucial role in assessing the health of the population (WHO 2006). With the agreement of WHO (World Health Organization), the residential housing is important, like a separate physical structure and in a link between the community (neighbors), too. Both of these factors influence a person's physical, mental and social status, so their importance is directly related to the welfare of society. European social policy is an integral part of the housing economic interest (EUR-Lex 2007b). Garage position problem is associated with the architectural and structural coherence, which influences housing comfort (Manzano-Agugliaro et al. 2015). Problems of garages of blocks or public buildings are solved, which are related to their ventilation, safety and economy (Pierce et al. 2015; Vasilevska et al. 2015), evaluation tools are considered and offered for the determination of the longterm environmental and social impacts in different dwellings as separate units (including garages). The situation of the garages of the single-family houses is being examined as one of the spatial areas of the house and overheating and ventilation problems are addressed. Due to continuously rising requirements of EPBD (Energy Performance of Buildings Directive), the Belgian scientists analyze the design parameters and conditions, ensuring good premises comfort in different thermal zones. To this end, the dwelling is divided into thermal zones (the garage is

Corresponding author: Romualdas Baušys

E-mail: romualdas.bausys@vgtu.lt 
attached to the auxiliary space) and thus the typical Flemish housing (Claes et al. 2015) is being simulated. Among the design parameters different garage position in respect of residential space is not considered in the study of these scientists. Study of other scientists (Nirvan et al. 2012) is associated with the impact of natural ventilation and mechanical ventilation systems for the residential space concerning garage installation. But the different positions of the garage are not considered in this case, also.

The purpose of our work is to choose a garage position in respect to of a residential house with multi-criteria methods searching for the physical and psychological comfort. To this end, firstly there were set 6 most popular object positions. The architects, recommendations of future single-family houses' owners, review of projects proposed in Lithuania are the basis for the choice of this set. It is understood that there cannot be one single solution for all the different cases (i.e. families of different size and age and dwellings). One should not compare the so-called "small houses" (up to $80 \mathrm{~m}^{2}$ ) intended for 1 or 2 person family with houses of the much bigger area and the requirements for them. Therefore, limits are set for the testing: economic class families with 3 to 5 persons with intended garage/carport ( 2 stands) for them next to the residential house. Today in most of describing parcel options the garages are going to be made for two cars $7.0 \times 7.0 \mathrm{~m}$ in size (minimum dimensions of the double garage, according to the Lithuanian legal documents is $6.0 \times 6.0 \mathrm{~m}$ (STR 2.02.09:2005)).

Urbanization problems are being solved with multicriteria methods associated with urban renewal (and thus the reclaiming of new parcels) and many other problems at least partly related to the garage positions in the parcels. In all cases, the selection of criteria (Azman et al. 2013) is one of the most important aspects of the study.

These aforementioned quite complicated decision problems can be effectively solved within multi-criteria decision making (MCDM) framework (Adnan et al. 2015; Jaskowski et al. 2014; Lee 2014; Vafaeipour et al. 2014). During the last decade a lot of the research has been done applying the fuzzy sets in the MCDM problem formulation (Aliakbari et al. 2015; Mardani et al. 2015). The application of these fuzzy sets allows taking into account the uncertainty of the initial information of the solution about the real life problems. Despite the fact that the various types of the fuzzy sets have been defined and applied to the solution of the MCDM problems they are not able to include all sorts of the vagueness into the mathematical model of the considered real engineering problem. The new neutrosophic sets allow dealing independently with the indeterminacy of the initial information (Bausys et al. 2015; Smarandache 1999). By the logic of the neutrosophic sets, each criterion of the MCDM problem is represented by three independent functions: the degree of the truth $(t)$, a degree of the indeterminacy $(i)$ and a degree of the falsity $(f)$.

The evolution of WASPAS method, which is applied to the solution of the considered problem, is presented below. The first extension of the original crisp WASPAS method (Chakraborty et al. 2015) that is constructed under interval-valued intuitionistic fuzzy set environment was performed by Zavadskas et al. (2014). Recently, a novel multiple attribute Weighted Sum-Product Assessment method with the gray attributes scores, namely WASPAS-G, was proposed in Zavadskas et al. (2015a). Turskis et al. (2015) proposed a fuzzy multi-attribute performance measurement (MAPM) framework, which incorporates the application of the novel Weighted Aggregated Sum-Product Assessment method with Fuzzy values (WASPAS-F) and Analytical Hierarchy Process (AHP). Zavadskas et al. (2015b) developed a new extension of WASPAS method, namely WASPAS-SVNS. The considered neutrosophic set provides the means to represent and model the vagueness of the initial information explicitly.

Different location selection problems have been solved within the framework of the multi-criteria decision making. Dheena and Mohanraj (2011) presented solution of the distribution center location problem. Elevli (2014) performed an evaluation of locations for the logistics center at Samsun (Turkey). Zavadskas et al. (2015c) solved a decision problem concerning the selection of the location for a deep-water port.

\section{Problem formulation for the selection of garage location}

It is important to identify the key factors while planning the construction of housing for a residence that determines the quality of human life. The optimal distribution of functional space has a significant impact not only in the house itself but in its parcel of land, also. According to the importance, the factors influencing the parcel's selection and construction situation in it can be listed as follows:

- Cardinal directions (North, East, South, West);

- Prevailing wind direction;

- Entrance location of the parcel;

- Intended place of the yard;

- Lookout opening from the parcel (to the city, forest, river and so on);

- Other (high neighbors house, location near the noisy road, specific features of the area and so on).

The factor "entrance location in the parcel" is directly associated with the car parking place. According to Technical Construction Regulation (STR 2.02.09:2005), there are restrictions in this regard: the parcel must have entrance to a private garage not narrower than $3.5 \mathrm{~m}$ wide, and the straightest and most convenient path for pedestrians from the street towards the main entrance to the house cannot cross or overlap with the auto road. Choosing a unique and exclusive parcel and aiming to build the best available house on it with the use of standard premises and parking lot layout plans will fail. However, most parcels do not have exclusions in specific terrain features, because they are usually rectangular in shape from 6 to 
10 acres plots adjoining the street, from which entrance location of the parcel should be made.

Number of cars in Lithuania according to statistics in 2016 compared with 2010 when 509 cars fell on 1000 people increased by 62 percent (Regitra 2016). Thus, today on average a family of 3 to 4 persons has 1 to 2 cars. Today single-family houses are not designed without car storage space. It is a closed and an open type garages or simply a space in the parcel intended for the car parking. Selection of garage type is determined by different criteria: from the architectural refinements of the parcel to the owner's wishes (Manzano-Agugliaro et al. 2015). The truth is that exist one aspect, which sometimes has a great significance, and it is regulated in Lithuanian legal documents. It is the total area (garage-open shelter is not counted in the total area of a single-family house). Closed type garages usually are designed near the building (when one wall is a partition between the living space and garage) and are integrated into the space of the house (when two walls are partitions between the living space and garage). Closed type garage as a separate building is normally estimated in the authoring projects when combining it with the parcel and building architecture. Open type garages (awnings) can be designed near the building or separately as a separate building.

The location of these parking lots can be evaluated according to certain criteria in order to reveal the peculiarities of alternative locations. When choosing a garage location according to the images found on the Internet or any other source of information, usually one chooses according to the aesthetic view of the other house. The importance of practicality and convenience, alternative possibilities of positions of the garage often are being reflected later when the project is already coordinated; it means too late (Alsaadani, De Souza 2016). Therefore, the owner should firstly decide whether the building will have a purely functional purpose or aesthetic highlight of the parcel, and also about the renovation prospects in case of an increase or changes in family composition, etc. Hence it is important to decide in advance and plan whether a garage will be built in conjunction with a house or away from it. So, the decision of the task is relevant for individuals who plan to design or are already designing their own housing in the parcels.

The accurate decision making in building industry is quite difficult and complicated problem (Ksiąźek et al. 2015). There can be numerous and diverse selection criteria for garage site: from the orientation of cardinal directions in the parcel to the adjacent neighbor's house height. We have selected four (in the expert opinion) the most important criteria $\left(c_{1}-c_{4}\right)$ :

- $c_{1}$ - the length of the foundation, $\mathrm{m}$;

- $c_{2}$ - internal functional communication, scores;

- $c_{3}$ - contextuality, scores;

$-c_{4}-$ aesthetics and others, scores.

Selection of criterion of foundation length is relevant because of the earthwork scope and construction cost. When the garage is being designed near to one façade of the house, the length of the garage foundation reduces by one-quarter, and after garage integration into the house space - even by three-quarters. In both cases, the rates of earthworks are falling because of excavation of the one and the same dip, equipment installation, etc. In the case of the awning, construction of individual foundations under the supports could not be linked with the house foundation. Internal functional communication describes the comfort of the use of single-family house units and compliance with user needs. Contextuality is defined as a forecast of options of zoning of the buildings in the parcel, depending from the parcel, orientation with respect to the cardinal directions. The last $c_{4}$ criterion includes aesthetics and other partially relevant (in expert opinion) aspects: insulation of residential premises dwelling (Motuziene et al. 2016; Balyani et al. 2015) because of the unheated garage, performance evaluation of garage insulation option and costs of other materials (walls and roof structures).

Particular geometric shape houses are designed and built traditionally in the mentioned rectangular parcels (Fig. 1): square, rectangular, cross- and L-shaped. The designed and installed garage can be situated on the front side of the house, and also from a facade, in the form of the house and stand separately.

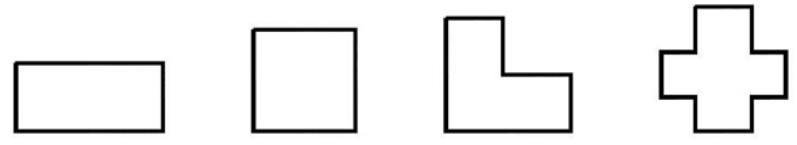

Fig. 1. Shapes of single-family houses

5 independent experts-designers and 2 future owners of the residential house performed the assignment of criteria importance.

\section{Alternatives}

For the construction of the considered alternatives, the analysis of the projects of the residential houses developed in Lithuania was performed. The projects are taken
1
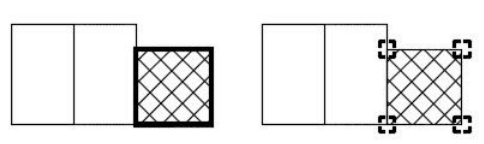

3

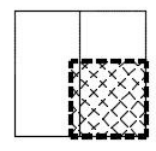

4

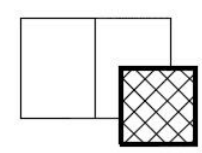

5

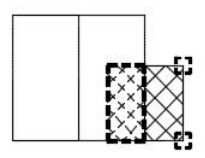

6

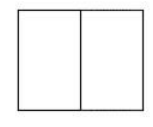

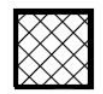

Fig. 2. Schemes of garage position in communication to the house 
into consideration involve only the houses with a total area of 80 to $300 \mathrm{~m}^{2}$ (House plans 2016). The analysis includes 251 projects that were created in the last 2-3 year period. There were distinguished six garages positions in relation to the house for the study, shown schematically in Figure 2.

The analysis of the above-mentioned projects shows that in the projects of the houses with a lowest common area, garages are usually not included or planned as open shelter. Projects where garages are not provided, we've assigned to the 6-th scheme.

All garages selected in the study are not insulated because insulation of $49 \mathrm{~m}^{2}$ garage would hardly respect the provisions of the European Parliament and Council Directives (Directive 2010/31/EU). In five of them, the garages are in one or another way integrated into the volume of the residential house.

\subsection{Garage position according to Scheme 1}

According to Scheme 1, the garage is designed near the main facade wall of the house (Fig. 3).

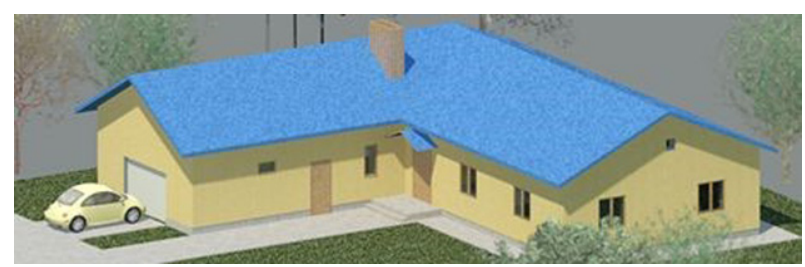

Fig. 3. Garage near the main facade side of the house

Construction of the foundations and supporting walls of the both buildings is closely related: the scale of land works and foundation price is a bit smaller because one wall of the garage is adjacent to the wall of a residential house. If there is no basement in the house, usually boiler-room is installed near the garage or other auxiliary space - in this way the heat is saved, which can be lost due to the non-heated garage. Internal connection with the residential premises is designed within the space of these premises. There will not be many options on the premises of the house and yard zoning by placing the garage on the northern side of the parcel (even if it is possible in accordance with site deployment of the parcel in relation to the cardinal directions). It is possible to achieve the desired integrity of the building by selecting the same house finish as the facade finish and the roof structure. This scheme corresponds to $26 \%$ if the analyzed the house projects.

\subsection{Garage position according to Scheme 2}

In the case of Scheme 2, the garage is designed near the house's main facade wall as in the Scheme 1, but the garage is installed without walls, it means open shelter (Fig. 4).

The volume of land works is the smallest because the foundation for the garage must be detached installed beneath two columns, then the foundation price will be

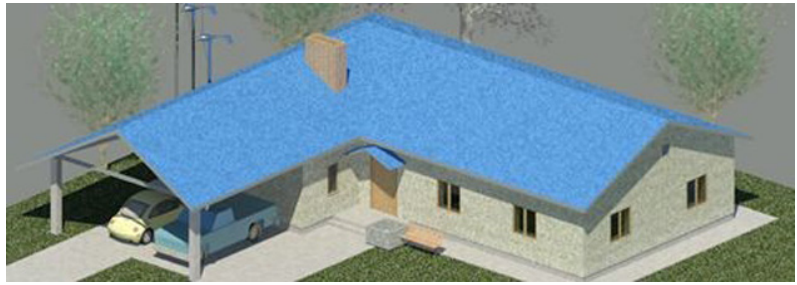

Fig. 4. Open shelter near the main facade side of the house

the lowest, and the walls of the entire installed. Communication with the residential premises is possible from the outside, but usually with a partition (roof) from the top. If the open shelter is designed from the main facade side of the house, the roof can be resolved by an extension of the roof of the residential house (depending on the architectural decision). If the intensity and the density of parcel's build-up are relevant to a particular parcel, then in the case of open shelter the solution is simple - it is not considered as a garage. This scheme covers $14 \%$ of the analyzed the house projects.

\subsection{Garage position according to Scheme 3}

In the case of Scheme 3, the garage is integrated into the house space (Fig. 5).

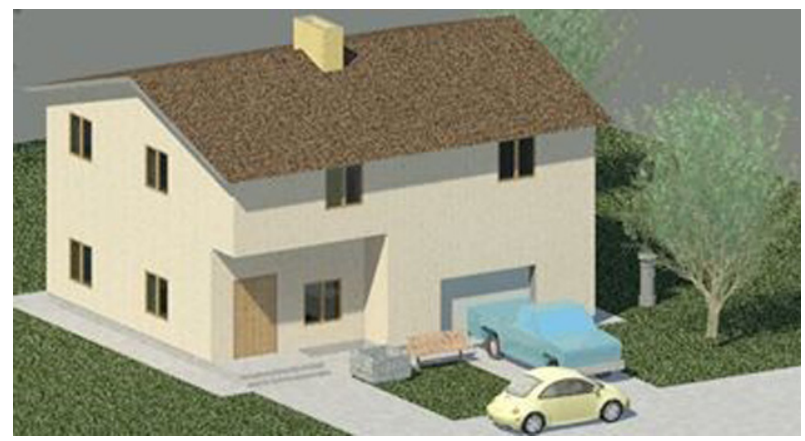

Fig. 5. Garage integrated into the house space

The volume of land works is the smallest (from the presented options), because one wall of the garage, generally coincides with the inner supporting, and beneath the other non-supporting wall can be installed, foundation only with one block in height (in the same way as beneath the brick partition of $12 \mathrm{~cm}$ ). Intercommunication with residential premises has the most options because two garage walls are inside the building. In this case, work and guest room or other premises are designed above the garage so not only two walls of the garage but also the overlap should be insulated. Thus, there will be the attic above the first floor (or the second floor), so the owner will have an additional investment (overlap, stairs). Depending on the deployment of the parcel in relation to the cardinal directions, the zoning of the premises and yard of the house is seen as the worst, because in the worst-case scenario, most rooms of the house can be directed to the north. This scheme involves $20 \%$ of the analyzed the house projects. 


\subsection{Garage position according to Scheme 4}

In the case of Scheme 4, the garage is partly integrated into a housing space (Fig. 6) as „stuffed” in the corner of the house.

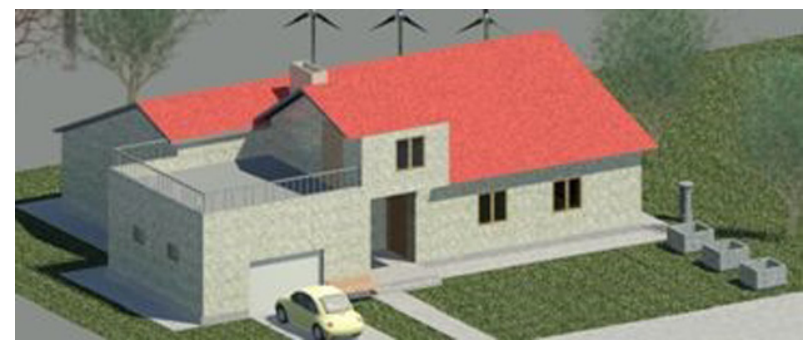

Fig. 6. Garage partially integrated into the house space

Unlike in the case of Scheme 3, all garage walls are load-bearing and the foundation is installed underneath them. Therefore, the length of the foundation is one of the biggest (from selected schemes). Intercommunication with residential premises is one of the bests because in part two garage walls are inside the building. Zoning of the premises of the house and the yard is seen as average. This alternative conforms to $5 \%$ of the analyzed the house projects.

\subsection{Garage position according to Scheme 5}

In the case of Scheme 5, the garage is divided into two spaces: closed and open (Fig. 5).

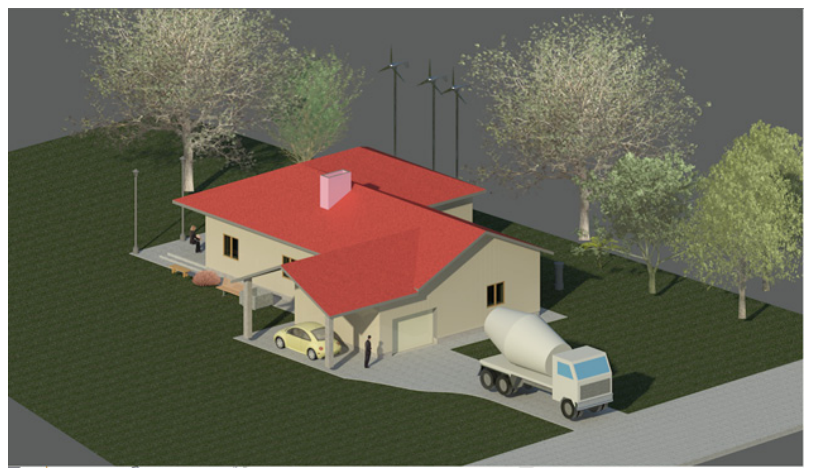

Fig. 7. The garage is divided into two spaces: closed and open

Options of installation of the foundation and intercommunication with residential premises are the same as those in Scheme 1, considering the fact that the individual awnings foundation installed at the same time. In this version, one wall is shared with accommodation, so commu- nication with them seen quite favorably. Possibility for a variant of a building layout in the parcel increases compared with the installation of a garage next to the facade wall. This alternative coheres with $14 \%$ of the analysed the house projects.

\subsection{Garage position according to Scheme 6}

In the case of Scheme 6, the garage is a freestanding building. Volumes of the land works and foundation price are among the highest. Contact with residential premises is external without any partitions, the worst of all. However, it is possible maximum variance in zoning the buildings in relation to the cardinal directions. Typically, such solution of the freestanding garage is taken when the parcel is a bit larger because the $3 \mathrm{~m}$ distance should be left until the parcel boundary. This solution would be more suitable for parcels with exclusive terrain features while choosing a unique combination of two buildings. This alternative goes together with $21 \%$ of the analyzed the house projects.

\section{Selection of the garage location by WASPAS- SVNS method}

Initially, for the WASPAS-SVNS method, criteria weights are needed to be determined. The weights of the criteria were calculated by applying AHP method (Table 1).

Table 1. Pairwise comparison of criteria

\begin{tabular}{c|cccc}
\hline & $c_{1}$ & $c_{2}$ & $c_{3}$ & $c_{4}$ \\
\hline$c_{1}$ & 1.00 & 0.20 & 0.25 & 0.33 \\
$c_{2}$ & 5.00 & 1.00 & 2.00 & 3.00 \\
$c_{3}$ & 4.00 & 0.50 & 1.00 & 2.00 \\
$c_{4}$ & 3.00 & 0.33 & 0.50 & 1.00 \\
& $q_{1}$ & $q_{2}$ & $q_{3}$ & $q_{4}$ \\
& 0.07 & 0.44 & 0.30 & 0.19 \\
CI/RI & 0.02 & & & \\
\hline
\end{tabular}

Initial decision matrix for garage location problem together with criteria weight is presented in Table 2.

For the solution of the formulated MCDM problem, the extension of WASPAS approach, namely WASPASSVNS, is applied. Originally WASPAS-SVNS method was applied to solve the site selection problem of the waste incineration plant (Zavadskas et al. 2015b). This method is constructed on the basis of the single-valued neutrosophic set. The considered approach to the solution

Table 2. Criteria and alternatives to weight ratio matrix

\begin{tabular}{l|c|c|c|c|c|c|c|c}
\hline & & Weight & $A_{1}$ & $A_{2}$ & $A_{3}$ & $A_{4}$ & $A_{5}$ & $A_{6}$ \\
\hline The length of the foundation, $\mathrm{m} c_{1}$ & $\min$ & 0.07 & 52 & 36 & 42 & 56 & 52 & 60 \\
Internal functional communication, scores, $c_{2}$ & $\max$ & 0.44 & 5 & 3 & 9 & 7 & 5 & 1 \\
Contextuality, scores, $c_{3}$ & $\max$ & 0.30 & 5 & 3 & 1 & 4 & 7 & 9 \\
Aesthetics and other, scores, $c_{4}$ & $\max$ & 0.19 & 4 & 9 & 1 & 5 & 7 & 2 \\
\hline
\end{tabular}


of the garage location selection problem can be outlined by the description of the separate steps:

1. The initial information consists of the evaluations concerning the ratings of the alternatives with respect to the criteria and the criterion weights. It can be presented by the following data $x_{i j}, i=1,2, \ldots, m ; j=1,2, \ldots, n$, which in fact is the aggregated expert evaluation of the $i^{\text {th }}$ alternative by the $j^{\text {th }}$ criterion. Therefore, the decision matrix will have the following form:

$$
X=\left[\begin{array}{cccc}
x_{11} & x_{12} & \cdots & x_{1 n} \\
x_{21} & x_{22} & \cdots & x_{2 n} \\
\vdots & \vdots & \ddots & \vdots \\
x_{m 1} & x_{m 2} & \cdots & x_{m n}
\end{array}\right] .
$$

2. At this step, the decision matrix $X$ is normalized by vector normalization technique, which can be expressed as:

$$
\tilde{x}_{i j}=\frac{x_{i j}}{\sqrt{\sum_{i=1}^{m}\left(x_{i j}\right)^{2}}} .
$$

3 . At the neutrosophication step, the obtained normalized decision matrix $\widetilde{X}$ in the crisp form is converted into the single-valued neutrosophic numbers. Therefore, the neutrosophic decision matrix $\widetilde{X}^{n}$ is calculated. In order to perform this action, the relationships between normalized values of the criteria of the alternatives and single-valued neutrosophic numbers are applied. The relationships between crisp and neutrosophic values are shown in Table 3.

Table 3. Crisp to neutrosophic conversion expressions describing the criteria of the alternatives

\begin{tabular}{l|c}
\hline \multicolumn{1}{c|}{ Crisp Normalized Values } & $\begin{array}{c}\text { Single-Valued Neutrosophic } \\
\text { Numbers }\end{array}$ \\
\hline Extremely good $(\mathrm{EG}) / 1.0$ & $(1.00,0.00,0.00)$ \\
Very very good (VVG)/0.9 & $(0.90,0.10,0.10)$ \\
Very good (VG $) / 0.8$ & $(0.80,0.15,0.20)$ \\
Good $(\mathrm{G}) / 0.7$ & $(0.70,0.25,0.30)$ \\
Medium good (MG)/0.6 & $(0.60,0.35,0.40)$ \\
Medium $(\mathrm{M}) / 0.5$ & $(0.50,0.50,0.50)$ \\
Medium bad (MB)/0.4 & $(0.40,0.65,0.60)$ \\
Bad (B)/0.3 & $(0.30,0.75,0.70)$ \\
Very bad (VB)/0.2 & $(0.20,0.85,0.80)$ \\
Very very bad (VVB) $/ 0.1$ & $(0.10,0.90,0.90)$ \\
Extremely bad (EB)/0.0 & $(0.00,1.00,1.00)$ \\
\hline
\end{tabular}

4. In line with the WASPAS-SVNS approach, the first decision component is based on the sum of the total relative importance of the alternative $i$ is calculated by the following equation:

$$
\tilde{Q}_{i}^{(1)}=\sum_{j=1}^{L_{\max }} \tilde{x}_{+i j}^{n} \cdot w_{+j}^{n}+\left(\sum_{j=1}^{L_{\min }} \tilde{x}_{-i j}^{n} \cdot w_{-j}^{n}\right)^{c},
$$

where $\tilde{x}_{+i j}^{n}$ and $w_{+j}^{n} \quad$ values are associated with the criteria to be maximized and $\tilde{x}_{-i j}^{n}$ and $w_{-j}^{n}$ values are associated with the criteria to be minimized. The multiplication of the neutrosophic variable and crisp real weight is calculated applying the equation as follows:

$$
\lambda \widetilde{N}_{1}=\left(1-\left(1-t_{1}\right)^{\lambda}, i_{1}^{\lambda}, f_{1}^{\lambda}\right), \lambda>0 .
$$

Here is necessary to mention, that single valued neutrosophic number can be expressed by $\widetilde{N}_{1}=\left(t_{1}, i_{1}, f_{1}\right), t$ corresponds to membership degree, $i-$ to indeterminacy degree and $t-$ to a non-membership degree. The summation of two single-valued neutrosophic numbers is performed as follows:

$$
\tilde{N}_{1} \oplus \tilde{N}_{2}=\left(t_{1}+t_{2}-t_{1} t_{2}, i_{1} i_{2}, f_{1} f_{2}\right) .
$$

The second term of the summation (Eqn (3)) consists of the complementary neutrosophic numbers, which are determined by equation:

$$
\tilde{N}_{1}^{c}=\left(f_{1}, 1-i_{1}, t_{1}\right) .
$$

5. The second term of the optimal alternative in the WASPAS-SVNS methodology is determined by applying the formulation of the product total relative importance of the alternative $i$ and is calculated by the following equation:

$$
\tilde{Q}_{i}^{(2)}=\prod_{j=1}^{L_{\max }}\left(\tilde{x}_{+i j}^{n}\right)^{w_{+j}^{n}} \cdot\left(\prod_{j=1}^{L_{\min }}\left(\tilde{x}_{-i j}^{n}\right)^{w_{-j}^{n}}\right)^{c} .
$$

The meaning of the terms of this equation is the same as in Eqn (4). The multiplication of the neutrosophic numbers is governed by the following equation:

$$
\tilde{N}_{1} \otimes \tilde{N}_{2}=\left(t_{1} t_{2}, i_{1}+i_{2}-i_{1} i_{2}, f_{1}+f_{2}-f_{1} f_{2}\right) .
$$

6. A final generalized criterion, which enables to rank the alternatives by the applied WASPAS-SVNS method is calculated as follows:

$$
\tilde{Q}_{i}=0.5 \tilde{Q}_{i}^{(1)}+0.5 \tilde{Q}_{i}^{(2)} .
$$

7. In the final step, the score function $S\left(\tilde{Q}_{i}\right)$ is calculated for all ranking alternatives $i=1,2, \ldots, m$ applying expression:

$$
S\left(\tilde{N}_{A}\right)=\frac{3+t_{A}-2 i_{A}-f_{A}}{4}
$$

and the final rankings of the alternatives can be performed by applying the descending order of the $S\left(\tilde{Q}_{i}\right), i=1$, $2, \ldots, m$. 
Table 4. The decision matrix $\widetilde{X}^{n}$ after the neutrosophication step

\begin{tabular}{ccccccc}
\hline \multirow{2}{*}{ Criteria } & \multicolumn{5}{c}{ Alternatives } \\
\cline { 2 - 6 }$c_{1} \min$ & $\mathrm{I}$ & $\mathrm{II}$ & $\mathrm{III}$ & $\mathrm{IV}$ & $\mathrm{V}$ & $\mathrm{VI}$ \\
& $(0.4471$, & $(0.3096$, & $(0.3612$, & $(0.4815$, & $(0.2752$, & $(0.5159$, \\
& 0.5793, & 0.7404, & 0.6888, & 0.5277, & 0.7748, & 0.4761, \\
\hline \multirow{2}{*}{$c_{2} \max$} & $0.5529)$ & $0.6904)$ & $0.6388)$ & $0.5185)$ & $0.7248)$ & $0.4841)$ \\
& $(0.3627$, & $(0.2176$, & $(0.6529$, & $(0.5078$, & $(0.3627$, & $(0.0725$, \\
& 0.6873, & 0.8324, & 0.2971, & 0.4882, & 0.6873, & 0.9275, \\
$c_{3} \max$ & $0.6373)$ & $0.7824)$ & $0.3471)$ & $0.4922)$ & $0.6373)$ & $0.9275)$ \\
\hline \multirow{2}{*}{$c_{4} \max$} & $(0.3716$, & $(0.2230$, & $(0.0743$, & $(0.2973$, & $(0.5203$, & $(0.6690$, \\
& 0.6784, & 0.8270, & 0.9257, & 0.7527, & 0.4695, & 0.2810, \\
& $0.6284)$ & $0.7770)$ & $0.9257)$ & $0.7027)$ & $0.4797)$ & $0.3310)$ \\
\hline
\end{tabular}

Table 5. Numerical results of WASPAS-SVNS

\begin{tabular}{ccccccc}
\hline & \multicolumn{6}{c}{ Alternatives } \\
\cline { 2 - 7 } & I & II & III & IV & V & VI \\
\hline \multirow{2}{*}{$\widetilde{Q}^{(1)}$} & $(0.9581$, & $(0.9724$, & $(0.9788$, & $(0.9618$, & $(0.9815$, & $(0.9364$, \\
& 0.0446, & 0.0259, & 0.0168, & 0.0388, & 0.0173, & 0.0615, \\
& $0.0482)$ & $0.0317)$ & $0.0201)$ & $0.0398)$ & $0.0218)$ & $0.0602)$ \\
\multirow{2}{*}{$\widetilde{Q}^{(2)}$} & $(0.1516$, & $(0.1222$, & $(0.0934$, & $(0.1758$, & $(0.1967$, & $(0.0779$, \\
& 0.8712, & 0.8980, & 0.9021, & 0.8393, & 0.8146, & 0.9223, \\
& $0.8484)$ & $0.8778)$ & $0.9066)$ & $0.8242)$ & $0.8033)$ & $0.9221)$ \\
\multirow{2}{*}{$\widetilde{Q}$} & $(0.6560$, & $(0.6890$, & $(0.7062$, & $(0.6720$, & $(0.7407$, & $(0.5866$, \\
& 0.3571, & 0.3098, & 0.2732, & 0.3337, & 0.2566, & 0.4094, \\
\multirow{2}{*}{$S(\widetilde{Q})$} & $0.3505)$ & $0.3049)$ & $0.2741)$ & $0.3295)$ & $0.2542)$ & $0.4093)$ \\
\hline \multirow{2}{*}{ Rank } & 0.6478 & 0.6912 & 0.7214 & 0.6687 & 0.7433 & 0.5896 \\
\hline
\end{tabular}

\section{Numerical example}

The solution of the garage location problem in the parcel for the residential house applying MCDM framework is given below. The obtained neutrosophic decision matrix after second and third steps of the applied WASPASSVNS approach is presented in Table 4.

The numerical results of the WASPAS-SVNS approach, illustrating the employment of the steps 4-7, are shown in Table 5. The final rankings of the alternatives shown in Table 5 are determined by the application of the score functions, which are defined by Eqn (11).

According to calculations made by WASPAS-SVNS method can be concluded that the best garage location is on facade side of the house (Alternative No 5). This solution can also be in principle applied to any house shape (Fig. 1) and a square case, even to all four sides of the house. For this best position of the garage, connection with the dwelling rooms can be organized in an internal or external ways as well (or both). The determined alternative provides the best building zoning options among all those studied alternatives, according to the wishes and needs of the many opportunities in their own way to install a garage appearance (wall finishes and roofing).

\section{Conclusions}

The obtained results can be applied for the parcels, which do not have exclusively specific terrain features, they must be approximately rectangular in shape from 6 to 10 acres plots adjoining the street, from which entrance location of the parcel should be made.

The garage location selection problem has been formulated including the following aspects: the price of the foundation, internal communication possibility, the orientation of the building layout in the parcel and aesthetics scores. The experts performed the evaluation of the criteria for the selection of the garage location. Processing this information by AHP method, there was determined that the most important criterion is an internal communication possibility.

To the solution of the aforementioned MCDM problem, the extension of the original crisp WASPAS method by the neutrosophic sets has been applied. Based on calculated results, the most appropriate location for the garage within residential parcel has been chosen. The best alternative is the case No 5. Comparing the two best alternatives is easy to observe that the presence of the best options of the alternative No 5 was governed by contextual- 
ity and aesthetics criteria for significance, despite worse internal functional communication criterion assessment.

\section{References}

Adnan, Y. M.; Daud, M. N.; Razali, M. N. M. 2015. A multicriteria framework for office tenants' preferences at office buildings, International Journal of Strategic Property Management 19(3): 271-282. https://doi.org/10.3846/1648715X.2015.1052586

Aliakbari, N. F.; Khalili, E. S.; Antucheviciene, J. 2015. A Hybrid MCDM Approach Based on Fuzzy ANP and Fuzzy TOPSIS for technology selection, Informatica 26(3): 369388. https://doi.org/10.15388/Informatica.2015.53

Alsaadani, S.; De Souza, C. B. 2016. Of collaboration or condemnation? Exploring the promise and pitfalls of architect-consultant collaborations for building performance simulation, Energy Research \& Social Science 19: 21-36. https://doi.org/10.1016/j.erss.2016.04.016

AM. 2007. Residents of the priorities of providing quality housing and the environment [online], [cited 22 July 2016]. Available from Internet: http://www.am.lt/VI/article.php3?article id=6689

Azman, M. N. A.; Ahamad, M. S. S.; Majid, T. A.; Yahaya, A. S.; Hanafi, M. H. 2013. Statistical evaluation of pre-selection criteria for industrialized building system (IBS), Journal of Civil Engineering and Management 19(1): S131-S140. https://doi.org/10.3846/13923730.2013.801921

Balyani, H. H.; Sohani, A.; Sayyaadi, H.; Karami, R. 2015. Acquiring the best cooling strategy based on thermal comfort and $3 \mathrm{E}$ analyses for small scale residential buildings at diverse climatic conditions, International Journal of Refrigeration 57: 112-137. https://doi.org/10.1016/j.ijrefrig.2015.04.008

Bausys, R.; Zavadskas, E. K.; Kaklauskas, A. 2015. Application of neutrosophic set to multicriteria decision making by COPRAS, Economic Computation and Economic Cybernetics Studies and Research (ECECSR) 49(2): 91-106.

Chakraborty, S.; Zavadskas, E. K.; Antuchevičienè, J. 2015. Applications of WASPAS method as a multi-criteria decision-making tool, Economic Computation and Economic Cybernetics Studies and Research (ECECSR) 49(1): 5-22.

Claes, K.; De Boever, L.; Breesch, H. 2015. Design recommendations for robust thermal summer comfort in residential lightweight buildings in a moderate climate, Energy Procedia 78: 2832-2837. https://doi.org/10.1016/j.egypro.2015.11.643

Dheena, P.; Mohanraj, G. 2011. Multicriteria decision-making combining Fuzzy Set theory, ideal and anti-ideal points for location site selection, Expert Systems with Applications 38(10): 13260-13265. https://doi.org/10.1016/j.eswa.2011.04.144

Directive 2010/31/EU of the European Parliament and of the Council of 19 May 2010 on the energy performance of buildings [online], [cited 24 February 2016]. Available from Internet: http://eur-lex.europa.eu/legal-content/en/ TXT/?uri=celex\%3A32010L0031

Elevli, B. 2014. Logistics freight center locations decision by using Fuzzy-PROMETHEE, Transport 29(4): 412-418. https://doi.org/10.3846/16484142.2014.983966

EUR-Lex. 2007a. Opinion of the Committee of the Regions Housing and regional policy (2007/C 146/02) [online], [cited 19 July 2016]. Available from Internet: http://eur-lex.europa.eu/legal-content/LT/TXT/?qid=14689 07564883\&uri=CELEX:52006AR0345

EUR-Lex. 2007b. Proposal for a Regulation of the European Parliament and of the Council on population and housing censuses /* COM/2007/0069 final - COD
2007/0032 */ [online], [cited 21 July 2016]. Available from Internet: http://eur-lex.europa.eu/legal-content/LT/ $\mathrm{TXT} /$ ?uri=CELEX\%3A52007PC0069

Eurostat. 2014. Eurostat, statistics explained [online], [cited 22 July 2016]. Available from Internet:

http://ec.europa.eu/eurostat/statistics-explained/index.php/ Housing statistics/lt

House plans [online], [cited 5 July 2016]. Available from Internet: http://www.namuplanai.lt/; http://lt.lt.allconstructions. com/portal/categories/459/namu-projektai; http://www.ekspertai.lt/individualiu_namu_projektai

Jaskowski, P.; Sobotka, A.; Czarnigowska, A. 2014. Decision model for selecting supply sources of road construction aggregates, Inzinerine Ekonomika - Engineering Economics 25(1): 13-20. https://doi.org/10.5755/j01.ee.25.1.3595

Ksiąźek, M. V.; Nowak, P. O.; Kivrak, S.; Rosłon, J. H.; Ustinovichius, L. 2015. Computer-aided decision-making in construction project development, Journal of Civil Engineering and Management 21(2): 248-259. https://doi.org/10.3846/13923730.2014.996250

Lee, W. S. 2014. A new hybrid MCDM model combining DANP with VIKOR for the selection of location - real estate brokerage services, International Journal of Information Technology \& Decision Making 13(1): 197-224. https://doi.org/10.1142/S0219622014500333

Manzano-Agugliaro, F.; Montoya, F. G.; Sabio-Ortega, A.; García-Cruz, A. 2015. Review of bioclimatic architecture strategies for achieving thermal comfort, Renewable and Sustainable Energy Reviews 49: 736-755. https://doi.org/10.1016/j.rser.2015.04.095

Mardani, A.; Jusoh, A.; Nor, K. M.; Khalifah, Z.; Zakwan, N.; Valipour, A. 2015. Multiple criteria decision-making techniques and their applications - a review of the literature from 2000 to 2014, Economic Research - Ekonomska Istraživanja 28(1): 516-571. https://doi.org/10.1080/1331677X.2015.1075139

Motuziene, V.; Rogoza, A.; Lapinskiene, V.; Vilutiene, T. 2016. Construction solutions for energy efficient single-family house based on its life cycle multi-criteria analysis: a case study, Journal of Cleaner Production 112: 532-541. https://doi.org/10.1016/j.jclepro.2015.08.103

Nirvan, G.; Haghighat, F.; Wang, L.; Akbari, H. 2012. Contaminant transport through the garage - House interface leakage, Building and Environment 56: 176-183. https://doi.org/10.1016/j.buildenv.2012.02.030

Pierce, G.; Willson, H.; Shoup, D. 2015. Optimizing the use of public garages: Pricing parking by demand, Transport Policy 44: 89-95. http://dx.doi:10.1016/j.tranpol.2015.07.003

Regitra 2016. Lithuanian road vehicle fleet has increased [online], [cited 22 July 2016]. Available from Internet: http:// www.regitra.lt/lt/naujienos/transporto registravimas/lietuvos_keliu_transporto_priemoniu_parkas_dar_padidejo

Smarandache, F. A. 1999. Unifying field in logics. Neutrosophy: Neutrosophic probability, set and logic. Rehoboth, USA: American Research Press.

STR 2.02.09:2005 Vienbučiai gyvenamieji pastatai, Valstybès žinios, 2005-08-02, No. 93-3464 [Single family residential houses]. Lithuanian Standard.

Turskis, Z.; Zavadskas, E. K.; Antuchevičienė, J.; Kosareva, N. 2015. A hybrid model based on Fuzzy AHP and Fuzzy WASPAS for construction site selection, International Journal of Computers, Communications \& Control (IJCCC) 10(6): 873-888.

Vafaeipour, M.; Zolfani, S. H.; Varzandeh, M. H. M.; Derakhti A.; Eshkalag, M. K. 2014. Assessment of regions priority for implementation of solar projects in Iran: New application of a hybrid multi-criteria decision making approach, Energy Conversion and Management 86: 653-663. https://doi.org/10.1016/j.enconman.2014.05.083 
Vasilevska, L.; Milanovic, D.; Nikolic, M.; Vranic, P.; Milojkovic, A. 2015. "Garage capitalism" as a form and process of post-socialist urban changes: Its pace, intensity and structural characteristics. A case study of Nis, Serbia, Habitat International 48: 149-158. https://doi.org/10.1016/j.habitatint.2015.03.022

WHO. 2006. Housing-health regulation in Europe [online], [cited 21 July 2016]. Available from Internet: http://www.euro.who.int/_data/assets/pdf_file/0004/ 121837/e89278.pdf

Zavadskas, E. K.; Antuchevicienè, J.; Seyed,H. R. H.; Shide, S.H. 2014. Extension of weighted aggregated sum product assessment with interval-valued intuitionistic fuzzy numbers (WASPAS-IVIF), Applied Soft Computing 24: 1013-1021. https://doi.org/10.1016/j.asoc.2014.08.031
Zavadskas, E. K.; Turskis, Z.; Antucheviciene, J. 2015a. Selecting a contractor by using a novel method for multiple attribute analysis: Weighted Aggregated Sum Product Assessment with grey values (WASPAS-G), Studies in Informatics and Control 24(2): 141-150.

Zavadskas, E. K.; Baušys, R.; Lazauskas, M. 2015b. Sustainable assessment of alternative sites for the construction of a waste incineration plant by applying WASPAS method with single-valued neutrosophic set, Sustainability 7(12): 15923-15936. https://doi.org/10.3390/su71215792

Zavadskas, E. K.; Turskis, Z.; Bagocius, V. 2015c. Multi-criteria selection of a deep-water port in the Eastern Baltic Sea, Applied Soft Computing 26: 180-192. https://doi.org/10.1016/j.asoc.2014.09.019

Romualdas BAUŠYS. Habil. Dr, Professor at the Department of Graphical Systems, Vilnius Gediminas Technical University (VGTU), Faculty of Fundamental Sciences, Lithuania. Research interests: multimedia processing, multi-criteria decision making, information technologies.

Birutė JUODAGALVIENĖ. Lecturer at the Department of Graphical Systems, Vilnius Gediminas Technical University (VGTU), Faculty of Fundamental Sciences, Lithuania. Research interests: engineering graphics in building design, building design, information technologies. 